Finding flies in the mushroom soup : Host specificity of fungus-associated communities revisited with a novel molecular method

Koskinen, Janne

2019-01

Koskinen, J , Roslin , T , Nyman , T , Abrego , N , Michell , C \& Vesterinen , E J 2019 , '

Finding flies in the mushroom soup : Host specificity of fungus-associated communities

revisited with a novel molecular method ', Molecular Ecology , vol. 28 , no. 2 , pp. 190-202 . https://doi.org/10.1111/

http://hdl.handle.net/10138/307615

https://doi.org/10.1111/mec. 14810

acceptedVersion

Downloaded from Helda, University of Helsinki institutional repository.

This is an electronic reprint of the original article.

This reprint may differ from the original in pagination and typographic detail.

Please cite the original version. 


\title{
Finding flies in the mushroom soup: Host specificity of fungus-associated communities revisited with a novel molecular method
}

\author{
Janne Koskinen $^{1,2}$ (D) | Tomas Roslin ${ }^{2,3}$ (ID $\mid$ Tommi Nyman $^{1}$ | Nerea Abrego² (D) | \\ Craig Michell $^{1}$ | Eero J. Vesterinen ${ }^{2,4}$
}

${ }^{1}$ Department of Environmental and Biological Sciences, University of Eastern Finland, Joensuu, Finland

${ }^{2}$ Department of Agricultural Sciences, University of Helsinki, Helsinki, Finland

${ }^{3}$ Department of Ecology, Swedish

University of Agricultural Sciences, Uppsala, Sweden

${ }^{4}$ Biodiversity Unit, University of Turku, Turku, Finland

Correspondence

Janne Koskinen, Department of Environmental and Biological Sciences, University of Eastern Finland, Yliopistokatu 7, PO Box 111, Joensuu FI-80101, Finland. Email: janne.koskinen@uef.fi

Funding information

Oskar Öflund Foundation; Olvi Foundation; Societas Entomologica Helsingforsiensis; Kuopio Naturalists' Society; Jane and Aatos Erkko Foundation

\begin{abstract}
Fruiting bodies of fungi constitute an important resource for thousands of other taxa. The structure of these diverse assemblages has traditionally been studied with labour-intensive methods involving cultivation and morphology-based species identification, to which molecular information might offer convenient complements. To overcome challenges in DNA extraction and PCR associated with the complex chemical properties of fruiting bodies, we developed a pipeline applicable for extracting amplifiable total DNA from soft fungal samples of any size. Our protocol purifies DNA in two sequential steps: (a) initial salt-isopropanol extraction of all nucleic acids in the sample is followed by (b) an extra clean-up step using solid-phase reversible immobilization (SPRI) magnetic beads. The protocol proved highly efficient, with practically all of our samples_-regardless of biomass or other properties-being successfully PCR-amplified using metabarcoding primers and subsequently sequenced. As a proof of concept, we apply our methods to address a topical ecological question: is host specificity a major characteristic of fungus-associated communities, that is, do different fungus species harbour different communities of associated organisms? Based on an analysis of 312 fungal fruiting bodies representing 10 species in five genera from three orders, we show that molecular methods are suitable for studying this rich natural microcosm. Comparing to previous knowledge based on rearing and morphology-based identifications, we find a species-rich assemblage characterized by a low degree of host specialization. Our method opens up new horizons for molecular analyses of fungus-associated interaction webs and communities.
\end{abstract}

\section{KEYWORDS}

community structure, DNA extraction and purification, ecological interaction networks, fungi, host specificity, metabarcoding

\section{1 | INTRODUCTION}

Metabarcoding (Taberlet, Coissac, Pompanon, Brochmann, \& Willerslev, 2012; Yu et al., 2012) has recently been successfully utilized for resolving both the nodes (species) and links (interactions) of natural communities (Roslin \& Majaneva, 2016). In terms of describing the nodes present, molecular approaches provide new resolution, both by uncovering cryptic taxa (Šigut et al., 2017) and by allowing the dissection of communities unamenable to morphological analyses, such as soil microbiota (Barberán, Bates, Casamayor, \& Fierer, 
2012; Tedersoo et al., 2014). In terms of links, metabarcoding allows us to study a wide variety of different interactions, such as pollination, predation or symbiosis (Clare, 2014; Roslin \& Majaneva, 2016). In terms of the architecture of such links, metabarcoding allows us to study a wide range of aspects, ranging from diet composition of individual species (Kaunisto, Roslin, Sääksjärvi, \& Vesterinen, 2017; Vesterinen et al., 2016) through host specificity of particular guilds or food web modules (Baker, Bittleston, Sanders, \& Pierce, 2016) to community-level structuring of trophic interactions (Geisen, Laros, Vizcaíno, Bonkowski, \& De Groot, 2015; Wirta et al., 2016).

The fruiting bodies of fungi constitute the resource base for a multitude of ecological communities and networks (Hammond \& Lawrence, 1989). Among macroscopic organisms, arthropods such as beetles and dipterans play a prominent role in fungus-associated networks. Nearly $50 \%$ of beetle families are at least partially associated with fungi, and the number of obligatory fungivorous beetle species ranges at least in the thousands (Hammond \& Lawrence, 1989; Lawrence, 1989). The same holds true for dipterans, among which sciarid fungus gnats alone encompass over 4,500 described species (Søli, Vockeroth, \& Matile, 2000). Mites (Acari) are likewise abundant in mycophagous arthropod communities (O'Connell \& Bolger, 1997; Yamashita \& Hijii, 2003). In addition to fungivorous arthropods, fruiting bodies also provide habitats for predatory, parasitic and opportunistic arthropod groups (e.g., Hammond \& Lawrence, 1989; Jonsell, González Alonso, Forshage, van Achterberg, \& Komonen, 2016; Lipkow \& Betz, 2005). Beyond arthropods, fungal fruiting bodies sustain a wide range of other taxa-in particular among microscopic organisms (Gams, Diederich, \& Põldmaa, 2004; Pent, Põldmaa, \& Bahram, 2017). Parasitic and decomposing fungi thrive on fruiting bodies, and so do bacteria of multiple orders and phyla (Gams et al., 2004; Pent et al., 2017, 2018).

By tradition, associations between fungi and associated arthropod taxa have been investigated by rearing adult arthropods from fruiting bodies, followed by morphological identification. This approach has been used to study competition (Ståhls, Ribeiro, \& Hanski, 1989), overall faunistic patterns (Hackman \& Meinander, 1979; Jakovlev, 2012; Ševčík, 2006) and, more recently, host specialization (Põldmaa et al., 2016). Yet, rearing-based studies are slow and work-intensive, and taxon-specific rearing mortality may lead to underestimation of species diversity. This can, in turn, bias inferences of community and food web structure (Wirta et al., 2014). In the same vein, studies of fungal associate taxa have been based on cultivation followed by morphological identification (Gams et al., 2004). Yet, only some fungal associates are actually cultivable outside their host, risking biases in the interpretation of community structure. From these perspectives, metabarcoding methods may offer not only a more cost-efficient, but also a more standardized and perhaps less biased route for investigating factors influencing the species composition and trophic structuring of fungus-associated communities.

A classical question targeted by rearing-based work is the degree of host specificity of fungus-feeding taxa. Rearing-based studies of insects have revealed, for example, clear differences in fungivore community composition between ephemeral and annual fungi
(Jonsell \& Nordlander, 2004; Põldmaa, Jürgenstein, Bahram, Teder, \& Kurina, 2015), as well as effects of host phylogeny and morphology on fungivore guild composition (Thorn et al., 2015). Molecular methods, in turn, have hinted at the presence of substantial cryptic diversity (Jürgenstein, Kurina, \& Põldmaa, 2015) and more limited host use than suggested by morphological analyses (Põldmaa et al., 2016).

While fungus-based communities may seem ideal targets for resolution by molecular techniques, several challenges have hindered the efficient application of such methods. The large size of many fruiting bodies poses challenges for sample handling and makes standard DNA extraction methods ungainly. More important, the complex chemical properties of fungi, such as high amounts of chitin, trehalose and secondary metabolites, have impaired the PCR steps critical in molecular analyses (California et al., 2012; Cubero, Crespo, Fatehi, \& Bridge, 1999; Haugland, Heckman, \& Wymer, 1999). The solutions developed to date have generally been optimized for relatively small-sized samples. Hence, when aiming to build further from previous efforts, we need a size-insensitive method for extracting PCR amplifiable DNA from fungal fruiting bodies.

In this study, we decided to aim for efficient and scalable methods for metabarcoding of the highly diverse communities inhabiting fungal fruiting bodies. Therefore, we first developed a pipeline applicable for extracting and purifying total genomic DNA from soft fungal samples of any size. As a proof of concept, we then applied our methods to address a topical ecological question: do different fungus species and taxa harbour distinct associated communities?

\section{MATERIALS AND METHODS}

\section{1 | Sampling design}

To evaluate the potential of DNA-based approaches to characterize communities associated with mushroom fruiting bodies, we targeted 12 species of basidiomycete fungi from five genera in three orders (Table 1). These species produce soft, ephemeral fruiting bodies and were chosen to represent locally common and socioeconomically important mycorrhizal taxa with different habitat preferences: Russula decolorans, Russula vinosa, Russula xerampelina coll. and Leccinum vulpinum are most common in Pinus stands, whereas Lactarius turpis, Lactarius trivialis and Boletus edulis favour Picea stands. The rest of the species show variable mycorrhizal associations with both conifers and broad-leaved trees. It is important to note that taxa associated with soft fungi (mushrooms and boletes) have been explored in much less detail than taxa associated with "hard fungi," such as perennial polypores (Jonsell \& Nordlander, 2004; Jonsell, Nordlander, \& Jonsson, 1999; Jonsell et al., 2016; Komonen, Jonsell, Økland, Sverdrup-Thygeson, \& Thunes, 2004; Komonen, Siitonen, \& Mutanen, 2001; Orledge \& Reynolds, 2005; Selonen, Ahlroth, \& Kotiaho, 2005; Yamashita et al., 2015). Our study therefore targets not only a methodological challenge, but also an ecological knowledge gap.

All samples were collected from southern and eastern Finland during July-September 2016 and 2017. The southernmost sampling locations were near Helsinki, Finland $\left(60.1^{\circ} \mathrm{N}, 24.9^{\circ} \mathrm{E}\right)$, the majority 
TABLE 1 The identity, taxonomic affinity and number of fruiting bodies analysed in this study, $n=312$

\begin{tabular}{|c|c|c|c|c|c|c|}
\hline Order & Family & Genus & Species & Samples & Main host trees & Main habitat \\
\hline \multirow[t]{2}{*}{ Agaricales } & \multirow[t]{2}{*}{ Cortinariaceae } & \multirow[t]{2}{*}{ Cortinarius } & C. armillatus & 22 & Pinus, Betula, Picea & All forest types \\
\hline & & & C. caperatus & 44 & Pinus, Picea, Betula & All forest types \\
\hline \multirow{5}{*}{ Russulales } & \multirow{5}{*}{ Russulaceae } & \multirow{3}{*}{ Russula } & R. paludosa & 24 & Pinus, Betula & All forest types \\
\hline & & & R. decolorans & 86 & Pinus & Prefers Pinus stands \\
\hline & & & Russula sp. & 1 & & \\
\hline & & \multirow[t]{2}{*}{ Lactarius } & L. trivialis & 28 & Picea, Betula & Prefers Picea stands \\
\hline & & & L. turpis & 12 & Picea, Betula & Picea stands \\
\hline \multirow[t]{2}{*}{ Boletales } & \multirow[t]{2}{*}{ Boletaceae } & Boletus & B. edulis & 4 & Picea & Picea stands \\
\hline & & Leccinum & L. versipelle & 8 & Betula & All forest types \\
\hline
\end{tabular}

Note. Main host trees denote the tree species in which the fruiting bodies are most commonly associated with. Main habitat denotes the woodland habitat type with which the fruiting bodies are most often associated in Finland south of northernmost Lapland. Nomenclature, ecological information and taxonomy are based on Salo et al. (2009).

around Joensuu, Finland $\left(62.6^{\circ} \mathrm{N}, 29.7^{\circ} \mathrm{E}\right)$, and the northernmost at Suomussalmi, Finland $\left(64.8^{\circ} \mathrm{N}, 28.9^{\circ} \mathrm{E}\right)$. Fruiting bodies were identified in the field based on recent literature (Salo, Niemelä, \& Salo, 2009). In the laboratory, six identifications for which ITS2 sequences were dominated by reads from a genus different from that identified in the field were judged dubious and removed. Each fruiting body was then placed in a separate resealable plastic bag, labelled and transferred to a $-21^{\circ} \mathrm{C}$ storage room during the same day. The resulting raw material consisted of 319 unique fruiting bodies. Of these fruiting bodies, the 42 largest ones were split into two to six subsamples for DNA extraction and metabarcoding, but read data from these subsamples were combined for each sample in the final data set.

\subsection{DNA extraction}

Fruiting bodies were homogenized in the laboratory using a handheld Bosch ${ }^{\circledR}$ MSM67160/01 blender, with replacement tips (catalogue number 00657259) sterilized in $2.5 \%$ sodium hypochlorite (bleach) solution for at least $1 \mathrm{hr}$ and then rinsed carefully before use. Total DNA was extracted from the homogenates using a modified salt extraction protocol (Aljanabi \& Martinez, 1997; Vesterinen et al., 2016) (see Protocol S1 for details). However, we further modified the protocol by including an extra purification step using SeraMag SPRI beads as the last step. This method was derived from Rohland \& Reich (2012) as further clarified by Faircloth and Glenn (2014) (see also Deangelis, Wang, \& Hawkins, 1995; Vesterinen et al., 2016). The full protocol can be summarized as follows: one volume (in our study $50 \mu \mathrm{l}$ ) of DNA extract and two volumes of SPRI bead solution were mixed and thoroughly vortexed. After 5 min of incubation at room temperature (RT), the sample was briefly centrifuged down and placed on a strong magnet rack until the solution was clear and a pellet was formed (usually in 1-3 min). Then, the supernatant (along with possible inhibitors) was removed and, while keeping the sample still on magnet, the pellet (containing only the DNA) was washed twice for 1 min with $150 \mu$ of freshly prepared $80 \%$ ethanol. After the second wash, all ethanol residues were carefully removed by drying the pellet for 3-10 min while still on the magnet. Here, it is essential that the pellet is dry of ethanol, whereas overdrying makes the subsequent elution step more difficult and decreases yield. Sterile water (equalling the volume of DNA extract introduced in the first step) was added to the sample. The sample was removed from the magnet, vortexed, incubated for $5 \mathrm{~min}$ at RT, centrifuged briefly and placed on the magnet. At last, the supernatant containing the purified DNA was transferred to a new tube.

Along with the samples, we ran nine negative controls through the protocol. Of these, one was a homogenization-phase control including only the lysis buffer, which was "homogenized" with the blender the same way as the real samples. The other eight were purification-phase controls, that is, samples containing $150 \mu \mathrm{l}$ of distilled water instead of DNA extracts, which were otherwise treated as the real samples.

\section{3 | PCR amplification}

To examine the potential for versatile molecular identification of multiple organismal groups from individual fruiting bodies, we attempted amplification of arthropods, fungal associates and bacteria from the full set of samples.

For metabarcoding of arthropod communities, we chose the most common marker used in molecular identification of animals: the mitochondrial cytochrome $c$ oxidase subunit I gene (COI) (Hebert, Ratnasingham, \& DeWaard, 2003). We amplified a 157-bp COI fragment with the primer pair ZBJ-Art1c and ZBJ-Art2c (Zeale, Butlin, Barker, Lees, \& Jones, 2011). For analysing communities of associated fungi, we chose the commonly used nuclear ribosomal internal transcribed spacer region 2 (ITS2) (Schoch et al., 2012; Seifert, 
2009), 327 bp of which were amplified with the primer pair ITS3_KYO2 and ITS4_KYO3 (Toju, Tanabe, Yamamoto, \& Sato, 2012). For bacterial communities, we used the widely applied $16 \mathrm{~S}$ ribosomal RNA gene; the 465-bp portion amplified by the primer pair Bakt_341F and Bakt_805R spans the variable V3 and V4 regions of $16 \mathrm{~S}$ (Herlemann et al., 2011). Primer information is collected in Supporting Information Table S1, with a critical evaluation of potential biases in the same section, Supporting Information Appendix S1.

For all primer pairs, we used a reaction volume of $10 \mu$, including $5 \mu \mathrm{l}$ of $2 \times$ MyTaq HS Red Mix (BIO-25048; Bioline, UK), $2.6 \mu \mathrm{l}$ of $\mathrm{H}_{2} \mathrm{O}, 0.2 \mu \mathrm{M}$ of each primer and $2 \mu \mathrm{l}$ of DNA extract. The PCR cycling conditions for the respective barcode regions were as follows:

1. COI: $3 \mathrm{~min}$ at $94^{\circ} \mathrm{C}$, then 16 cycles of $94^{\circ} \mathrm{C}$ for $30 \mathrm{~s}, 61^{\circ} \mathrm{C}$ for $30 \mathrm{~s}$ and $72^{\circ} \mathrm{C}$ for $30 \mathrm{~s}$, followed by 24 cycles of $94^{\circ} \mathrm{C}$ for $30 \mathrm{~s}$, $53^{\circ} \mathrm{C}$ for $30 \mathrm{~s}$ and $72^{\circ} \mathrm{C}$ for $30 \mathrm{~s}$, followed by $72^{\circ} \mathrm{C}$ for $10 \mathrm{~min}$.

2. ITS2: $95^{\circ} \mathrm{C}$ for $10 \mathrm{~min}$, then 35 cycles at $94^{\circ} \mathrm{C}$ for $20 \mathrm{~s}, 47^{\circ} \mathrm{C}$ for $30 \mathrm{~s}$ and $72^{\circ} \mathrm{C}$ for $20 \mathrm{~s}$, followed by $72^{\circ} \mathrm{C}$ for $7 \mathrm{~min}$.

3. $16 \mathrm{~S}: 95^{\circ} \mathrm{C}$ for $5 \mathrm{~min}$, then $25 \mathrm{cycles}$ of $95^{\circ} \mathrm{C}$ for $40 \mathrm{~s}, 55^{\circ} \mathrm{C}$ for $2 \mathrm{~min}$ and $72^{\circ} \mathrm{C}$ for $1 \mathrm{~min}$, followed by $72^{\circ} \mathrm{C}$ for $7 \mathrm{~min}$.

\subsection{Library preparation}

We used a dual indexing approach; that is, both forward and reverse primers were tagged with different indexing barcodes (Shokralla et al., 2015). All samples included a unique index combination to track the reads correctly after sequencing. Library preparation followed Vesterinen et al. (2016) with minor modifications: For a reaction volume of $10 \mu \mathrm{l}$, we mixed $5 \mu \mathrm{l}$ of $2 \times$ MyTaq HS Red Mix, $2 \mu \mathrm{l}$ of sterile $\mathrm{H}_{2} \mathrm{O}, 0.3 \mu \mathrm{M}$ of each primer and $2.6 \mu$ of locus-specific PCR product. The PCR cycling conditions were $5 \mathrm{~min}$ in $95^{\circ} \mathrm{C}$, then 15 cycles of $20 \mathrm{~s}$ in $95^{\circ} \mathrm{C}, 15 \mathrm{~s}$ in $60^{\circ} \mathrm{C}$ and $30 \mathrm{~s}$ in $72^{\circ} \mathrm{C}$, followed by $5 \mathrm{~min}$ in $72^{\circ} \mathrm{C}$. Following Aizpurua et al. (2018), Alberdi, Aizpurua, Gilbert, and Bohmann (2018) and Kaunisto et al. (2017), we refrained from measuring the DNA concentration of individual libraries and instead pooled $2.5 \mu \mathrm{l}$ of each indexed sample per sequencing run (i.e., each pool consisted of samples amplified with either COI or ITS+16S primers), then cleaned pools using dual SPRI purification to remove any possible artefacts or nontarget size amplicons (Wirta et al., 2015). Sequencing was performed on an Illumina MiSeq platform at the Functional Genomics Unit of the University of Helsinki, Finland. For the pooled arthropod library, we used v2 (300 cycles) $2 \times 150$ bp paired-end sequencing, and for the fungal and bacterial data, we used v3 (600 cycles) $2 \times 300$ bp sequencing. Pooled ITS2 and $16 \mathrm{~S}$ libraries were sequenced simultaneously, but the run included two independent PCR and indexing replicates of each DNA extract (i.e., sample or subsample) for both markers.

\section{5 | Bioinformatics}

The three sequencing runs yielded the following amounts of qualitycontrolled paired-end reads: The arthropod COI library produced $16,182,449$ reads, of which $11,165,977$ could be assigned to samples with unique indexing barcodes. The two replicate sequencing runs involving pooled fungal ITS2 and bacterial 16S libraries produced altogether 23,182,536 reads, of which 18,773,401 were assigned to samples.

The FASTQ files were uploaded to the servers of the CSC - IT Center for Science (www.csc.fi)—for trimming and further analysis. Paired-end reads were merged and trimmed for quality using USEARCH version 9 (Edgar, 2010), and primers were removed using cutadapt version 1.11 (Martin, 2011). The reads were then collapsed into unique sequences (singletons removed), chimeras were removed, and reads were clustered into ZOTUs and mapped back to the original trimmed reads to establish the total number of reads in each sample using USEARCH UNOISE3 command (Edgar \& Flyvbjerg, 2015).

After filtering, our raw data set consisted of 2,303,923 $\mathrm{COI}$, 3,430 112 ITS2 and 3,547 12316 S reads that could be mapped to original samples. The arthropod ZOTUs were identified to species or, when species name could not be achieved, to BINs (Ratnasingham \& Hebert, 2013) using the Python script package bold-retriever v. 1.0.0 (Vesterinen et al., 2016) or custom scripts. For the Arthropoda COI data, we removed rare species or OTUs that were found in fewer than 10 samples (only two OTUs removed in this step) and those samples with fewer than 10 reads (71 samples removed). Fungal OTUs were initially filtered for ITS2 reads using ITSx software (Bengtsson-Palme et al., 2013), then assigned to taxa using the UNITE database (UNITE Community, 2017) with QIIME (Caporaso et al., 2010) and an E-value cut-off of 0.0001. For this purpose, we focused on samples yielding at least one thousand reads. We also validated the identity of each analysed fruiting body based on the ITS2 data set; this resulted in removal of six samples in which the identification based on ITS2 reads contrasted strongly (dominance of wrong host taxon with over 1,000 reads) with the species name recorded in the field. At last, to omit host taxa from community analyses of fungal associates, we discarded all OTUs that represented the species and/ or genera of fungi explicitly sampled. Bacterial OTUs were identified to species sensu lato using SINTAX algorithm with RDP classifier (Edgar, 2016) with a probability cut-off of 0.8. For final analyses, we used negative controls as a minimum threshold. In other words, we subtracted the maximum number of reads found in any negative control from the read counts observed in the ecological samples.

Before combining outputs from the two $16 \mathrm{~S}$ amplification and indexing replicates, we used the $16 \mathrm{~S}$ data sets to assess the repeatability of our metabarcoding approach. For this, we first processed the two sequence sets individually using the $\mathrm{DaDa} 2$ v. 1.6.0 (Callahan et al., 2016) pipeline in $R$ ( $R$ Core Team, 2017) and then generated nonmetric multidimensional scaling (NMDS) ordination plots based on Bray-Curtis distances (Bray \& Curtis, 1957) among samples (including replicates and subsamples of the same fruiting body) with the phyloseq package v. 1.23.1 (McMurdie \& Holmes, 2013) in R.

\subsection{Statistical analyses}

To visualize the arthropod-fungus interactions structures resolved by our molecular data, we used package bipartite (Dormann, Frund, 
Bluthgen, \& Gruber, 2009) in R to construct a quantitative food web based on relative read abundance (number of OTU reads/sum of all OTU reads) of arthropods in each sample of each host fungus species. We chose to use relative read count data as a proxy for arthropod abundance, as supported by Piñol, Senar, and Symondson (2018) and Deagle et al. (2018).

To visualize similarities of arthropod, fungal and bacterial communities across fungal samples and taxa, we used NMDS ordination based on intersample Bray-Curtis dissimilarity index values as implemented in the package vegan (Oksanen et al., 2015) in R. For the $\mathrm{COI}$ data set, we used all samples containing more than one identifiable arthropod OTU after the trimming scheme explained in Bioinformatics section. For the ITS2 data set, we used samples containing more than one identifiable OTU with at least 1,000 or more fungal OTU reads. Because the final $16 \mathrm{~S}$ data set consisted of 3,370 species or taxa, and as it was not possible to produce NMDS ordinations with acceptable stress values (i.e., values below 0.2), we reduced the dimensions of the data by removing those bacterial species with prevalence equal to or below $5 \%$ among the sampling units. To account for differences in sequencing depth, we divided the number of reads of each OTU in each sample by the total number of reads in the sample. These data were then square-root-transformed prior to running the NMDS analysis.

At last, we quantified host specificity by fitting joint species distribution models to the arthropod, fungal and bacterial data using the Hierarchical Modelling of Species Communities (HMSC) $\mathrm{R}$ package (Ovaskainen et al., 2017). This modelling framework allowed us to measure the community-level responses of all taxa identified to taxonomic variation among fungal hosts. In the fitted models, we included the presence-absence of the molecularly identified species at the level of individual fruiting bodies as the response matrix, and the species and orders of the host fungi as categorical explanatory variables. For computational reasons, in the case of the bacterial data set the analyses were limited to those species with a prevalence higher than $10 \%$ among the sampling units (a criterion fulfilled by 920 species). To control for variation in sequencing depth, we included the log-transformed number of reads as a continuous explanatory variable. We modelled the presence-absence data using a probit link function and measured the effect of each of the explanatory variables by performing the variance partitioning procedure described in Ovaskainen et al. (2017).

\section{RESULTS}

\section{1 | Overall success metrics}

As compared to standard salt extraction, our novel method for DNA extraction and purification clearly improved PCR amplification success (Supporting Information Figure S1). Therefore, we were able to amplify arthropod COI barcodes from the vast majority of samples: of an original 318 fruiting bodies, after discarding the six dubious identifications of the fungal host species (see Sampling design), and two samples that failed during sequencing, we retained a pool of 310 samples suitable for COI analyses. Of these, 295 (95\%) yielded sequences attributable to at least one arthropod taxon. This high rate of success was achieved despite the large and variable size of the original fruiting bodies. The trimmed, pruned and filtered molecular data set used for the analyses consisted of two acarid, six arachnid, two collembolan and 200 insect species, collectively representing 59 different families in 12 orders (Supporting Information Table S2). Of the arthropods, 74 could only be assigned to family or higher taxa, although all of these could be assigned to a BIN, which is a close approximation to a biological species but for some reason (e.g., new or cryptic species) lacking a species name (Ratnasingham \& Hebert, 2013). The most common insect groups were the dipteran families Phoridae, Muscidae, Chironomidae, Anthomyiidae and Mycetophilidae, and the coleopteran family Staphylinidae. A total of 260 samples yielded two or more arthropod taxa, and 133 samples yielded 10 or more identified taxa.

For ITS2 and 16S, the final data set included 312 unique fruiting bodies (Table 1). In ITS2 sequences, 865 (of a total of 1,166) OTUs passed ITSx filtering, and 649 of these were identified as fungal ITS2. In total, 3,243 185 could be assigned to a taxon with a $100 \%$ match to reference sequences in the UNITE database. As expected, the majority (over $80 \%$ ) of these reads represented the fungal taxa and genera of the sampled fruiting bodies. After filtering out evident host reads, the final community data consisted of 465,003 reads representing 613 OTUs, of which 81 could be identified to a specific species, 188 to a genus, 71 to a family and the rest to a higher level or left unassigned. The most common classes were Leotiomycetes, Agaricomycetes and Dothideomycetes, with Helotiales being by far the most common order with a total of 172 OTUs. A total of 269 samples yielded two or more and 185 samples 10 or more identifiable OTUs.

For bacterial $16 \mathrm{~S}$ analyses, 3,469 OTUs passed $16 \mathrm{Sx}$ filtering. The final combined bacterial data set consisted of 2,689 225 reads of 3,370 OTUs, which could be identified with $80 \%$ certainty based on comparisons to reference databases. Of these, 1,057 OTUs could be identified to level comparable to genus, 656 to family, 323 to order and the rest to class or higher levels.

Sample-specific sequence contents resulting from the two independent $16 \mathrm{~S}$ amplification and indexing replicates were generally highly consistent, which was reflected as a tendency for sample replicates to a position close to each other in NMDS ordination space (Supporting Information Figure S2A). This general tendency extended to subsamples of large fruiting bodies (Supporting Information Figures S2B and S3).

\section{2 | Imprints of host taxonomy on fungus- associated communities}

Different species of fungi shared a wide variety of arthropods with each other, with even abundant arthropod taxa showing no strong links to particular fungal genera or orders (Figure 1). As a consequence of this general lack of specialization in arthropod-fungus 


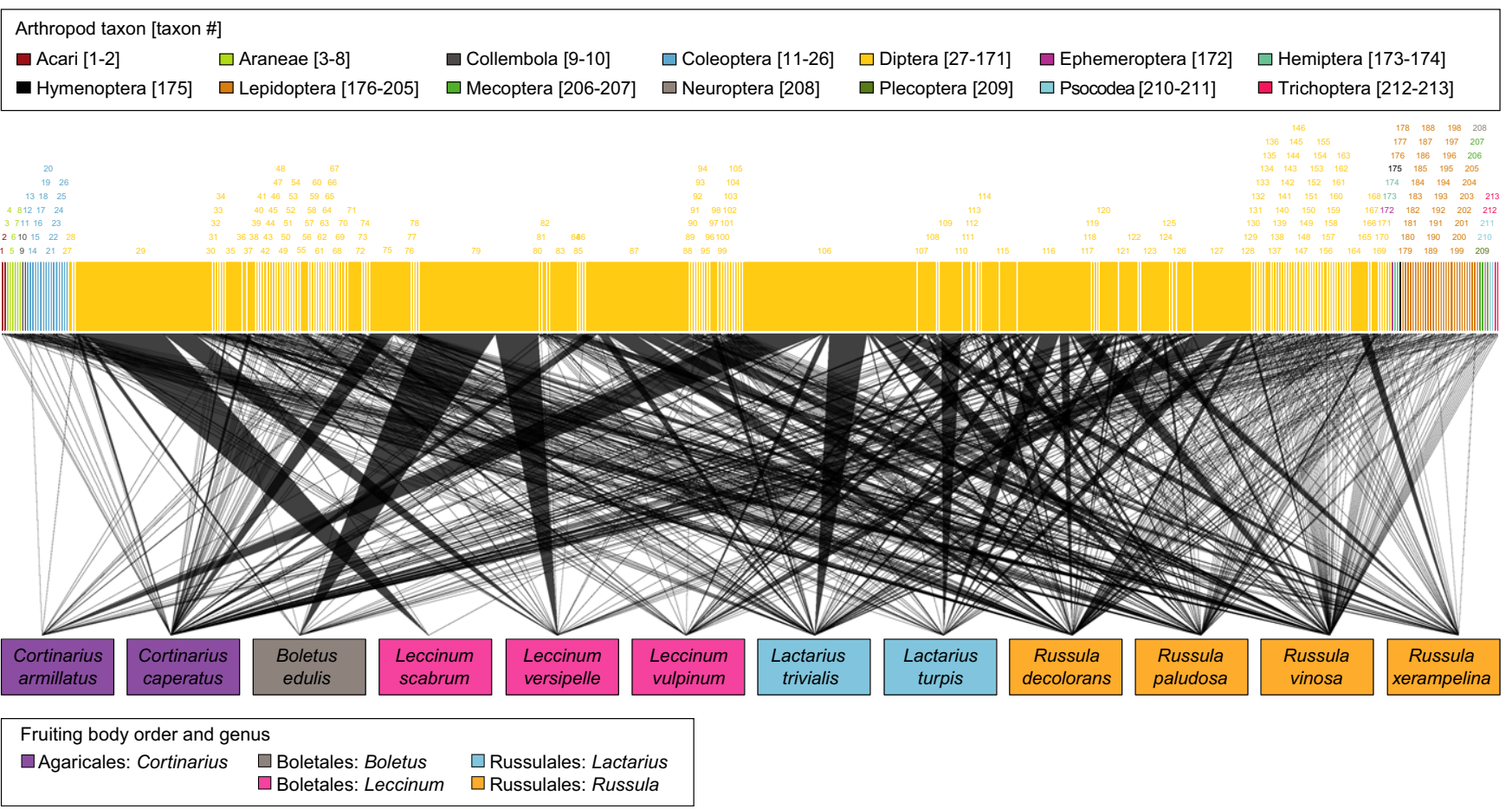

FIGURE 1 A quantitative interaction network based on relative read abundance of arthropods in each sample of each host fungus species. The upper blocks show arthropod species revealed by metabarcoding, and the lower blocks refer to studied fungal species. The systematic affinity of arthropods and fungi is indicated by colours (see legend). The thickness of the lines connecting arthropods with fungi represents the proportional abundance of each detected interaction event. Full names for arthropod taxon numbers are given in Supporting Information Table S2

(a) Arthropod communities

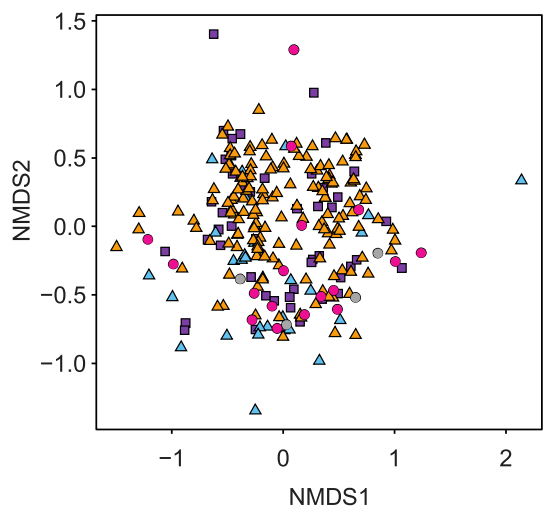

(b) Fungal associate communities

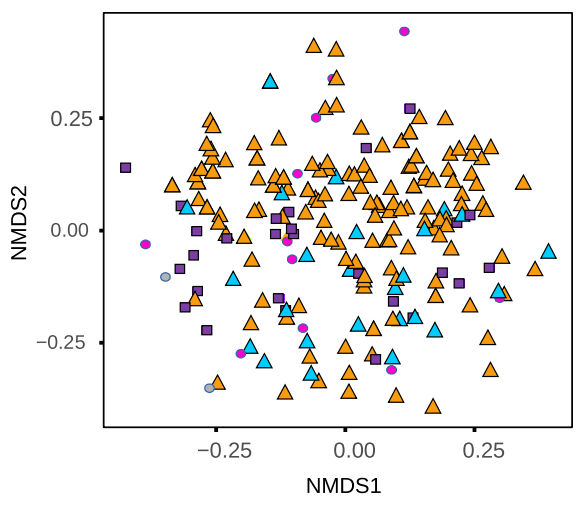

(c) Bacterial communities

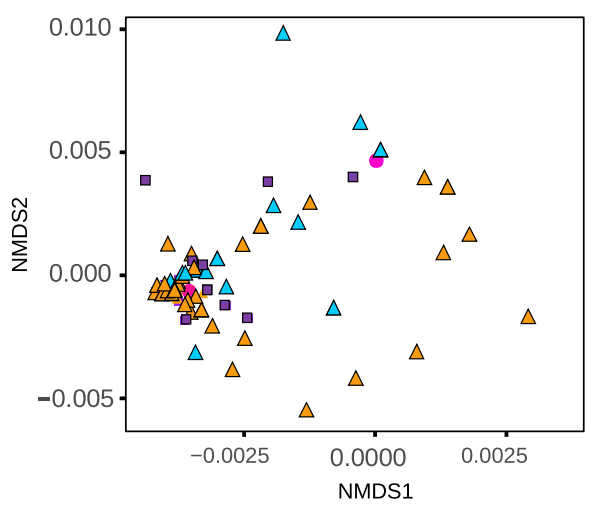

FIGURE 2 Nonmetric multidimensional scaling (NMDS) ordination of the community compositions of (a) arthropods, (b) fungal associates and (c) bacterial taxa in fruiting bodies of the focal fungal host taxa. In all panels, symbols denote the order to which the host species belongs, and different colours indicate genera (see legend)

associations, communities associated with different host fungi were generally highly similar, so that samples representing specific fungal genera and orders overlapped broadly in NMDS ordination space
(Figure 2a). Similar broad overlaps were found in NMDS ordinations based on communities of fungal associates (Figure $2 b$ ) and bacterial taxa (Figure 2c). 
Results from our HMSC analyses were in line with the ordination-based inferences: averaged over species, the fitted HMSC models explained only $18 \%, 15 \%$ and $45 \%$ of the variation in arthropod, fungal and bacterial occurrences in the fruiting bodies, respectively. However, within each associate group, the amount of variance explained by the models differed considerably across species (Figure 3). It is important that the overall amount of explained variance was not constrained by taxonomy, but rather by the prevalence of the species in the data sets: The highest $R^{2}$ values were obtained for OTUs with medium-level prevalence, that is, for the ones with the highest potential for variation in their occurrence patterns (Supporting Information Figure S4).

In terms of the proportion of variance explained by the taxonomy of the host fungal species and sequencing depth, the three associate communities showed very similar patterns. Of the variance explained in arthropod community structure, the order and species of the fruiting body accounted for an average of $27 \%$ and $28 \%$, respectively, while sequencing depth explained $22 \%$ (Figure 3a). For the community of other fungi associated with the focal fungal fruiting bodies, host order and species explained an average of $29 \%$ and $25 \%$, respectively, and sequencing depth accounted for $7 \%$ (Figure $3 \mathrm{~b}$ ). In the case of the bacterial community, the order and species of the fruiting body explained an average of $31 \%$ and $27 \%$, respectively, while sequencing depth accounted for $16 \%$ (Figure 3c).

\section{DISCUSSION}

In this study, we present a new method for simple sampling of fungivorous communities along with their substrate-regardless of substrate size. With this method, we achieved a high success rate in inferring communities of associated taxa from fungal fruiting bodies of complex chemical composition and highly variable mass. In evidence of its efficiency in answering ecological questions, we used the method to revisit classic concepts of specialization and generalism in fungus-associated communities. Our findings suggest a low level of host specificity and little imprint of fungal taxonomy on community structures of arthropods, fungal associates and bacterial taxa. Compared to previous studies, they offer relatively high estimates of species richness per fungal host taxon. Below, we address each finding in turn.

\subsection{A new method}

In developing our new protocol, we aimed for a method that would (a) consistently produce good-quality DNA for biome characterization, (b) be scalable across samples of vastly different size, (c) be economically feasible (i.e., cheap), (d) require little dedicated equipment and (e) present no health hazards, thus excluding methods based on phenol extraction (California et al., 2012). To minimize the time spent on method development, we naturally based it on previously established protocols. As a result of the above criteria, our protocol is suitable for almost any molecular ecology laboratory, with little investment in extra equipment.

A key innovation in the protocol-and a step of significant importance for reducing the final cost-is the combination of classic, affordable and easily adjustable salt-isopropanol extraction with a more refined purification step. The decision to use chaotropic salting procedures was based on previous work by Pilipenko, Salmela, and Vesterinen (2012) and Vesterinen et al. (2016). However, pilot tests with extracted fungal material showed high rates of PCR failure, potentially due to massive contamination with impurities (such as polysaccharides) coextracted along with the target DNA, which inhibited any later PCR steps (Supporting Information Figure S1). This finally led us to attempt SPRI purification. In evidence of the purification success achieved, the current method yielded identifiable arthropod DNA from $94 \%$ of the samples, and this high success rate extends to DNA from other associated taxa. Disregarding the quantitatively dominant DNA of the fruiting bodies themselves, $86 \%$ of samples yielded ITS2 sequences identifiable to associated fungi. In terms of bacteria identified based on $16 \mathrm{~S}$ sequences, the main clades found were consistent with those reported by Pent et al. (2017) as being common among boreal forest mushrooms. That the method yielded reliable, repeatable data on bacterial community structure was also confirmed by the general similarity of communities among the two 16S PCR replicate data sets (Supporting Information Figures S2 and S3). In combination, these findings suggest that our method yields DNA useful for characterizing the full fungus-associated microbiome.

It is important that as the protocol was designed with cost efficiency in mind, it remains within the reach of even research teams lacking expensive equipment. The current presequencing price estimate is ca. $1 €$ per sample, as based on $0.15 €$ for salt extraction, 0.15 $€$ for SPRI purification and $0.7 €$ for PCR and library preparation. Thus, the protocol is fully applicable to ecologically relevant sample sizes.

If possible, the reproducibility of our results should be confirmed by positive controls with known concentrations of known species (De Barba et al., 2014), and we recommend that such initiatives be implemented in near future. At the same time, we should acknowledge the practical limitations of such validation. As long as we are dealing with communities as poorly known and described as fungusassociated bacteria and fungus-associated fungi, it will be logically impossible to formulate complete, appropriate positive controls-as we simply do not know the full set of organisms which are there to detect. This is something of a Catch-22 (Heller, 1961) for anyone trying to establish the validity of a system in which new taxa may be detected. We suggest that it is best resolved by the iterative approach of first identifying the set of component phyla, as in the current study, and then verifying their detectability in future work.

\subsection{Host specificity revisited}

How the identity and properties of a living resource structure its associated community remains a question at the core of modern 
(a) Arthropod community

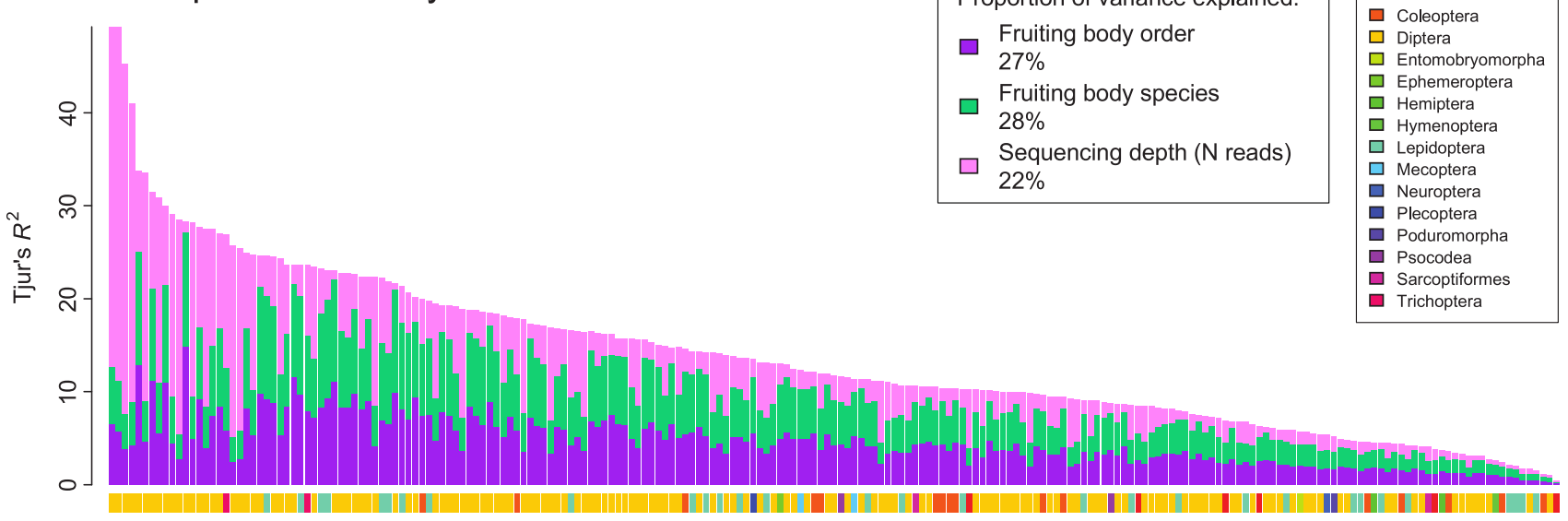

Arthropod species and taxon (b) Fungal associate community

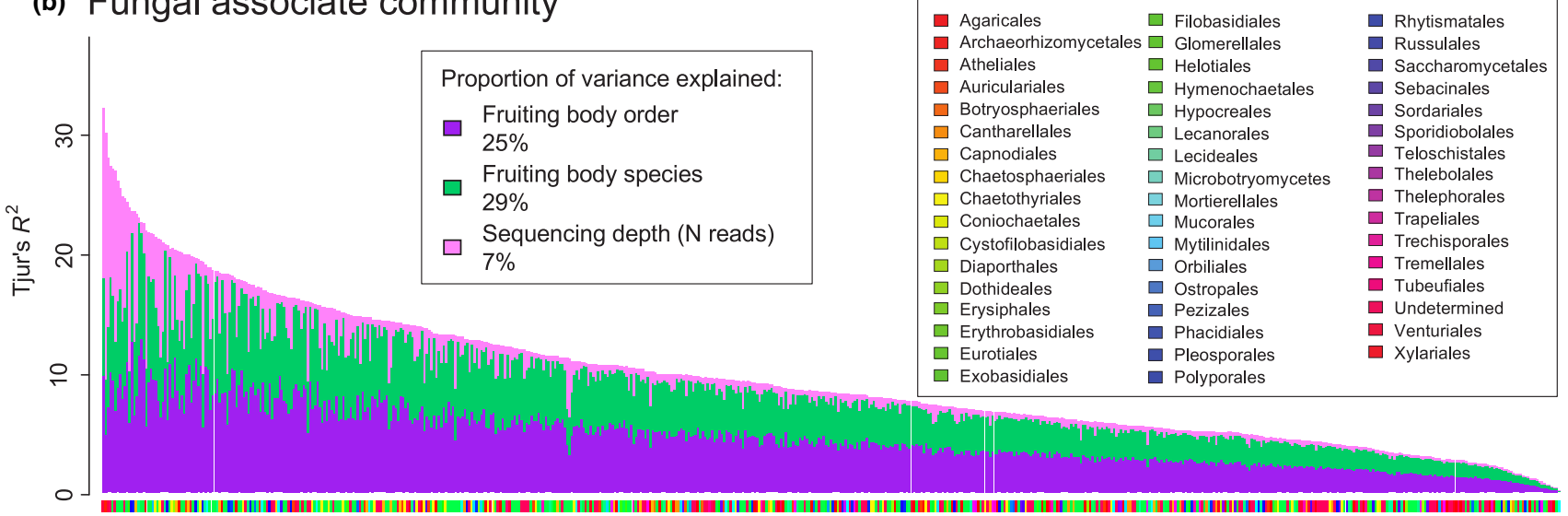

Fungal associate species and taxon (c) Bacterial community

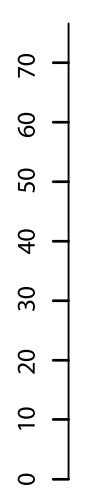

Proportion of variance explained:

Fruiting body order

$31 \%$

Fruiting body species

$29 \%$

Sequencing depth ( $\mathrm{N}$ reads)

$14 \%$

Bacteria species

FIGURE 3 Amount of variance explained by the joint species distribution model for each of the (a) arthropod, (b) fungal associate and (c) bacterial taxa. The species have been sorted according to the total amount of variance explained by the models. The amount of variance explained by fungal host species, fungal host order and sequencing depth is indicated by different colours on the bars (see legend). The numbers in legends show the average variation explained as the proportion of total variance explained. Bar colours below the x-axes in (a) and (b) indicate the taxonomic group that each associate species belongs to (see legend) 
community ecology (Lamit et al., 2015). Where host phylogeny has often been assumed to leave a strong imprint on associated communities (Cadotte, Albert, \& Walker, 2013; Gerhold, Cahill, Winter, Bartish, \& Prinzing, 2015; Mouquet et al., 2012), we found little trace of such effects among communities associated with soft-bodied, ephemeral fungi. This inference was consistently supported by major overlap in feeding links between arthropods and different fungi (Figure 1), by extensive overlap in the arthropod, and fungal and bacterial associated communities of different fungi (Figure 2), and by the generally low fraction of variation in community structure attributable to host identity and taxonomy (Figure 3). As a technical reminder, we note that the relatively high $R^{2}$ values observed for bacterial communities reflect a general association between incidence and variance explained (Supporting Information Figure S4). From the bacterial data, the rarest and therefore most unpredictable species were explicitly removed from the analyses, resulting in elevated $R^{2}$ values.

The observed lack of specialization among all organism groups associated with all the soft mushrooms studied here is consistent with the ephemeral and patchy nature of fungal resources, which should promote generalist associations and polyphagy (Hanski, 1989). What is still worth emphasizing is that the faunas and floras examined here represent a mix of presumptively more and much less obligate fungus-associated taxa. Thus, the general pattern reported does not preclude the existence of some specialists. Indeed, previous rearing-based work has described variable degrees of host specialization among fungivorous arthropods (Hackman \& Meinander, 1979; Komonen, 2003; Krivosheina, 2008; Polevoi, Jakovlev, \& Zaitzev, 2006; Schigel, 2012). Such variation may reflect different patterns of specialization to different types of fungi. Fungivore specialization among bracket fungi-which usually develop long-lived and harder fruiting bodies than do the mushroom-producing fungi examined here-has been found to vary with the morphological, chemical and phenological properties of the host species (Epps \& Arnold, 2010; Orledge \& Reynolds, 2005). Estimating some general level of host specificity among all fungivores may then—per definition-be a futile task. Much rather, we might focus our efforts on resolving variation in host specificity and the ecological correlates thereof. As a special case, among fungivores inhabiting the ephemeral, soft fruiting bodies of fungi examined by us, several species of Pegomya flies have been previously proposed to specialize on the basidiomes of the Boletales clade (Ståhls et al., 1989). In our data set, we found three identified Pegomya species, none of which showed a particular association with boletes. The common species $P$. geniculata proved present in both gilled fungi and boletes, thus contradicting the traditional perception of the high specificity of Pegomya to boletes (Hackman \& Meinander, 1979).

Of late, Põldmaa et al. (2015) found differences in communities associated with saprotrophic vs. ectomycorrhizal fungi and suggested that host phylogenetic richness will be positively linked with the richness of mycetophilid fungus gnats (Sciaroidea s.l.). Thus, while our current study points to generalist associations as a common pattern among fungus-associated taxa, further work will be needed to dissect associations between fungi of different characteristics on the one hand, and associated organisms with different life cycles and traits on the other hand. For such work, the protocol presented here offers the ideal instrument.

As a further point worth noting, our hierarchical models of fungus-associated species communities revealed a large amount of variation not attributable to host identity, taxonomy or sequencing depth (Figure 3). The reasons for this variation remain unknown, but could include a wide variety of effects, including - but not limited to -habitat and microhabitat type (Jakovlev, 2011), forest management history (Niemelä, 1997; Økland, 1994), overall variation in the surrounding resource patch dynamics (Heard, 1998) and-perhaps most crucially-variation in the age and decay stage of the sampled fruiting body (Epps \& Arnold, 2010; Ståhls et al., 1989). When a fruiting body ages and starts to decompose, it changes in composition, meaning that young and old fungi will provide different resource patches. In line with this reasoning, in perennial polypores, specialist insect species may tend to colonize younger fruiting bodies, while generalists sometimes use older and dying ones (Jonsell \& Nordlander, 2004; Yamashita et al., 2015). While in the current study we restricted variation in mushroom age to more effectively tackle questions related to the effect of host identity, we will next use the methods developed here to dissect impacts of host ageing and habitat characteristics on community patterns among arthropods, fungi and bacteria associated with soft mushrooms (J. Koskinen, T. Roslin, N. Abrego, E. Vesterinen, \& T. Nyman, in prep.).

\section{3 | Comparisons with previous studies}

By metabarcoding a total of 312 unique fruiting bodies from 13 species representing five genera and three orders (Table 1), we compiled and analysed a data set of 210 arthropod species, including dipterans from 25 different families. By comparison, studies using traditional methods have certainly yielded massive ecological data sets. For example, Põldmaa et al. (2015) reared a total of 11,040 fungus gnats from 340 fruiting bodies representing 81 species and 24 genera of fungi, identifying a total of 37 fungus gnat species alone and a total of 16 dipteran families. Hackman and Meinander (1979) reared about 120 species of Diptera from over 1,200 fruiting bodies representing 184 fungus species, and Ševčík (2006) detected a total of 242 dipteran species from 248 fungal species over the period of 12 years. Yamashita et al. (2015) discovered a total of 82 coleopteran species from 427 fruiting bodies from 22 genera when sampling tropical bracket fungi, which often produce hard and long-lived fruiting bodies. While these numbers could easily be translated to simple metrics of host specificity — such as number of associated species per host taxon-the different resolution and the different biases associated with different methods often render direct comparisons between metrics of ecological interaction structure problematic (Morris, Gripenberg, Lewis, \& Roslin, 2014; Pellissier et al., 2018; Wirta et al., 2014). Simple metrics of host specialization will namely vary with the set of host fungi included for comparison and thus with the study design. Thus, in the current context, we content 
ourselves with stating that, on average, we detected 16 fungus-associated arthropods per host fungus species and of 0.68 species per individual fruiting body.

While taken at their face value, these may appear high numbers, and they would certainly change with a different set of fungi examined. What we emphasize is that our sampling design was explicitly based on multiple fungal host species from each of multiple fungal orders, that neither host species nor order offered much of an imprint, and that this pattern was consistent among arthropods, fungi and bacteria. Consistent with the previous section (see Host specificity revisited), all of these considerations attest to low overall host specificity, with little imprint of host phylogeny.

\section{5 | CONCLUSIONS}

To our knowledge, our study represents the first large-scale analysis of fungus-feeding arthropod, fungal and bacterial associates of basidiomycete fungi based on a metabarcoding approach. We were able to design a robust method for extracting high-quality total DNA from different-sized fungal samples. This method is simple, safe and economic enough to be applied in any basic molecular laboratory. Most important, it allows us to revisit fundamental ideas about how fungus-associated communities are assembled and structured. In the current pilot study, we have used it to define data-driven hypotheses about the patterning of these diverse communities. Next, the resulting combination of tools and concepts will allow us to dissect the drivers of host specificity in fungus-associated biomes, as based on massive and purpose-generated materials.

\section{ACKNOWLEDGEMENTS}

We wish to thank the University of Eastern Finland Doctoral Programme in Environmental Physics, Health and Biology, and the University of Helsinki for monetary and material support. Kadri Põldmaa (University of Tartu) and Olavi Kurina (Estonian University of Life Sciences) provided kind input and feedback. Kirsten Miller (Swedish University of Agricultural Sciences) offered precious information on fungal and bacterial bioinformatics. Marjo Kilpinen and Eija Takala (University of Helsinki) were invaluable in laboratory work, and Tuomas Kankaanpää contributed extra samples. This study was financially supported by the Oskar Öflund Foundation, the Olvi Foundation, Societas Entomologica Helsingforsiensis, the Kuopio Naturalists' Society and the Jane and Aatos Erkko Foundation. We acknowledge CSC, IT Center for Science Ltd., Espoo, Finland, for the allocation of computational resources.

\section{DATA ACCESSIBILITY}

Analytical scripts, as well as labelled raw reads and OTUs, will be made available in the Dryad Digital Repository once the article is accepted for publication under https://doi.org/10.5061/dryad.tf56f m1.

\section{AUTHOR CONTRIBUTIONS}

JK, TN, TR and EV designed the research. JK conducted the sampling. EV designed and supervised the laboratory protocol. JK and EV conducted the molecular work. EV and CM did the bioinformatics. NA, CM and JK analysed the data. TN and JK finished figures. JK, TR and TN wrote a first draft of the manuscript, which was then further revised by all authors.

\section{ORCID}

Janne Koskinen (iD http://orcid.org/0000-0002-5396-575X

Tomas Roslin (iD http://orcid.org/0000-0002-2957-4791

Nerea Abrego iD http://orcid.org/0000-0001-6347-6127

Eero J. Vesterinen (iD http://orcid.org/0000-0003-3665-5802

\section{REFERENCES}

Aizpurua, O., Budinski, I., Georgiakakis, P., Gopalakrishnan, S., Ibañez, C., Mata, V., ... Alberdi, A. (2018). Agriculture shapes the trophic niche of a bat preying on multiple pest arthropods across Europe: Evidence from DNA metabarcoding. Molecular Ecology, 27(3), 815-825. https://doi.org/10.1111/mec.14474

Alberdi, A., Aizpurua, O., Gilbert, M. T. P., \& Bohmann, K. (2018). Scrutinizing key steps for reliable metabarcoding of environmental samples. Methods in Ecology and Evolution, 9(1), 134-147. https://doi.org/10. 1111/2041-210X.12849

Aljanabi, S., \& Martinez, I. (1997). Universal and rapid salt-extraction of high quality genomic DNA for PCR-based techniques. Nucleic Acids Research, 25(22), 4692-4693. https://doi.org/10.1093/nar/25.22.4692

Baker, C. C. M., Bittleston, L. S., Sanders, J. G., \& Pierce, N. E. (2016). Dissecting host-associated communities with DNA barcodes. Philosophical Transactions of the Royal Society B: Biological Sciences, 371, 20150328. https://doi.org/10.1098/rstb.2015.0328

Barberán, A., Bates, S. T., Casamayor, E. O., \& Fierer, N. (2012). Using network analysis to explore co-occurrence patterns in soil microbial communities. ISME Journal, 6(2), 343-351. https://doi.org/10.1038/is mej.2011.119

Bengtsson-Palme, J., Ryberg, M., Hartmann, M., Branco, S., Wang, Z., Godhe, A., ... Nilsson, R. H. (2013). Improved software detection and extraction of ITS1 and ITS2 from ribosomal ITS sequences of fungi and other eukaryotes for analysis of environmental sequencing data. Methods in Ecology and Evolution, 4(10), 914-919. https://doi.org/10. 1111/2041-210X.12073

Bray, J. R., \& Curtis, J. T. (1957). An ordination of the upland forest communities of Southern Wisconsin. Ecological Monographs, 27(4), 325 349. https://doi.org/10.2307/1942268

Cadotte, M., Albert, C. H., \& Walker, S. C. (2013). The ecology of differences: Assessing community assembly with trait and evolutionary distances. Ecology Letters, 16(10), 1234-1244. https://doi.org/10.1111/ ele.12161

California, B., Vazquez-Angulo, J. C., Mendez-Trujillo, V., González-Mendoza, D., Morales-Trejo, A., Grimaldo-Juarez, O., \& Cervantes-Díaz, L. (2012). A rapid and inexpensive method for isolation of total DNA from. Genetics and Molecular Research, 11(2), 1379-1384. https://doi. org/10.4238/2012.May. 15.8

Callahan, B. J., McMurdie, P. J., Rosen, M. J., Han, A. W., Johnson, A. J. A., \& Holmes, S. P. (2016). DADA2: High-resolution sample inference from Illumina amplicon data. Nature Methods, 13(7), 581-583. https://doi.org/10.1038/nmeth.3869 
Caporaso, J. G., Kuczynski, J., Stombaugh, J., Bittinger, K., Bushman, F. D., Costello, E. K., ... Knight, R. (2010). QIIME allows analysis of high-throughput community sequencing data. Nature Publishing Group, 7(5), 335-336. https://doi.org/10.1038/nmeth0510-335

Clare, E. L. (2014). Molecular detection of trophic interactions: Emerging trends, distinct advantages, significant considerations and conservation applications. Evolutionary Applications, 7(9), 1144-1157. https://d oi.org/10.1111/eva.12225

Cubero, O. F., Crespo, A., Fatehi, J., \& Bridge, P. D. (1999). DNA extraction and PCR amplification method suitable for fresh, herbariumstored, lichenized, and other fungi. Plant Systematics and Evolution, 216(3-4), 243-249. https://doi.org/10.1007/BF01084401

De Barba, M., Miquel, C., Boyer, F., Mercier, C., Rioux, D., Coissac, E., \& Taberlet, P. (2014). DNA metabarcoding multiplexing and validation of data accuracy for diet assessment: Application to omnivorous diet. Molecular Ecology Resources, 14(2), 306-323. https://doi.org/10. 1111/1755-0998.12188

Deagle, B. E., Thomas, A. C., Mclnnes, J. C., Clarke, L. J., Vesterinen, E. J., Clare, E. L., ... Eveson, J. P. (2018). Counting with DNA in metabarcoding studies: How should we convert sequence reads to dietary data? Molecular Ecology, 0-3, https://doi.org/10.1111/mec.14734

Deangelis, M. M., Wang, D. G., \& Hawkins, T. L. (1995). Solid-phase reversible immobilization for the isolation of PCR products. Nucleic Acids Research, 23(22), 4742-4743. https://doi.org/10.1093/nar/23. 22.4742

Dormann, C. F., Frund, J., Bluthgen, N., \& Gruber, B. (2009). Indices, graphs and null models: Analyzing bipartite ecological networks. The Open Ecology Journal, 2(1), 7-24. https://doi.org/10.2174/ 1874213000902010007

Edgar, R. C. (2010). Search and clustering orders of magnitude faster than BLAST. Bioinformatics, 26(19), 2460-2461. https://doi.org/10. 1093/bioinformatics/btq461

Edgar, R. C., \& Flyvbjerg, H. (2015). Error filtering, pair assembly and error correction for next-generation sequencing reads. Bioinformatics, 31(21), 3476-3482. https://doi.org/10.1093/bioinformatics/btv401

Edgar, R. (2016). SINTAX: A simple non-Bayesian taxonomy classifier for 16S and ITS sequences. BioRxiv, 074161, https://doi.org/10.1101/ 074161

Epps, M. J., \& Arnold, E. (2010). Diversity, abundance and community network structure in sporocarp-associated beetle communities of the central Appalachian Mountains. Mycologia, 102(4), 785-802. https://d oi.org/10.3852/09-161

Faircloth, B. C., \& Glenn, T. C. (2014). faircloth-lab serapure protocol, Release 2.3. https://doi.org/10.6079/j9mw2f26

Gams, W., Diederich, P., \& Põldmaa, K. (2004). Fungicolous fungi. In G. M. Mueller, M. S. Foster, \& G. F. Bills (Eds.), Biodiversity of fungi (pp. 343-392). Burlington, VT: Elsevier. https://doi.org/10.1016/b978012509551-8/50020-9

Geisen, S., Laros, I., Vizcaíno, A., Bonkowski, M., \& De Groot, G. A. (2015). Not all are free-living: High-throughput DNA metabarcoding reveals a diverse community of protists parasitizing soil metazoa. Molecular Ecology, 24(17), 4556-4569. https://doi.org/10.1111/mec. 13238

Gerhold, P., Cahill, J. F., Winter, M., Bartish, I. V., \& Prinzing, A. (2015). Phylogenetic patterns are not proxies of community assembly mechanisms (they are far better). Functional Ecology, 29(5), 600-614. https://doi.org/10.1111/1365-2435.12425

Hackman, W., \& Meinander, M. (1979). Diptera feeding as larvae on macrofungi in Finland. Annales Zoologici Fennici, 16(1), 50-83.

Hammond, P. M., \& Lawrence, J. F. (1989). Mycophagy in insects: A summary. In N. Wilding, N. M. Collins, P. Hammond, \& J. F. Webber (Eds.), Insect-fungus interactions (pp. 275-324). London, UK: Academic Press. https://doi.org/10.1016/b978-0-12-751800-8.50018-5

Hanski, I. (1989). Fungivory: Fungi, insects and ecology. In N. Wilding, N. M. Collins, P. M. Hammon, \& J. F. Webber (Eds.), Insect-fungus interactions (pp. 25-68). London, UK: Academic Press. https://doi. org/10.1016/b978-0-12-751800-8.50008-2

Haugland, R. A., Heckman, J. L., \& Wymer, L. J. (1999). Evaluation of different methods for the extraction of DNA from fungal conidia by quantitative competitive PCR analysis. Journal of Microbiological Methods, 37 (2), 165-176. https://doi.org/10.1016/S0167-7012(99)00061-5

Heard, S. B. (1998). Resource patch density and larval aggregation in mushroom-breeding flies. Oikos, 81(1), 187. https://doi.org/10.2307/ 3546480

Hebert, P. D., Ratnasingham, S., \& DeWaard, J. R. (2003). Barcoding animal life: Cytochrome $c$ oxidase subunit 1 divergences among closely related species. Proceedings of the Royal Society of London. Series B: Biological Sciences, 270(Suppl 1), S96. https://doi.org/10.1098/rsbl. 2003.0025

Heller, J. (1961). Catch-22. New York, NY: Simon \& Schuster.

Herlemann, D. P. R., Labrenz, M., Jürgens, K., Bertilsson, S., Waniek, J. J., \& Andersson, A. F. (2011). Transitions in bacterial communities along the $2000 \mathrm{~km}$ salinity gradient of the Baltic Sea. ISME Journal, 5(10), 1571-1579. https://doi.org/10.1038/ismej.2011.41

Jakovlev, J. (2011). Fungus gnats (Diptera: Sciaroidea) associated with dead wood and wood growing fungi: New rearing data from Finland and Russian Karelia and general analysis of known larval microhabitats in Europe. Entomologica Fennica, 22(3), 157-189. https://doi.org/ 10.1111/ele.12757

Jakovlev, J. (2012). Fungal hosts of mycetophilids (Diptera: Sciaroidea excluding Sciaridae): A review. Mycology: An International Journal on Fungal Biology, 3(1), 11-23. https://doi.org/10.1080/21501203.2012. 662533

Jonsell, M., González Alonso, C., Forshage, M., van Achterberg, C., \& Komonen, A. (2016). Structure of insect community in the fungus Inonotus radiatus in riparian boreal forests. Journal of Natural History, 50(25-26), 1613-1631. https://doi.org/10.1080/00222933.2016.1145273

Jonsell, M., \& Nordlander, G. (2004). Host selection patterns in insects breeding in bracket fungi. Ecological Entomology, 29(6), 697-705. https://doi.org/10.1111/j.0307-6946.2004.00654.x

Jonsell, M., Nordlander, G., \& Jonsson, M. (1999). Colonization patterns of insects breeding in wood decaying fungi. Journal of Insect Conservation, 3(2), 145-161.

Jürgenstein, S., Kurina, O., \& Põldmaa, K. (2015). The Mycetophila ruficollis Meigen (Diptera, Mycetophilidae) group in Europe: Elucidating species delimitation with $\mathrm{COI}$ and ITS2 sequence data. ZooKeys, 508, 15-51. https://doi.org/10.3897/zookeys.508.9814

Kaunisto, K. M., Roslin, T., Sääksjärvi, I. E., \& Vesterinen, E. J. (2017). Pellets of proof: First glimpse of the dietary composition of adult odonates as revealed by metabarcoding of feces. Ecology and Evolution, 7 (20), 8588-8598. https://doi.org/10.1002/ece3.3404

Komonen, A. (2003). Hotspots of insect diversity in boreal forests. Conservation Biology, 17(4), 976-981. https://doi.org/10.1046/j.15231739.2003.02076.x

Komonen, A., Jonsell, M., Økland, B., Sverdrup-Thygeson, A., \& Thunes, K. (2004). Insect assemblage associated with the polypore Fomitopsis pinicola: A comparison across Fennoscandia. Entomologica Fennica, 15 (2), 102-112.

Komonen, A., Siitonen, J., \& Mutanen, M. (2001). Insects inhabiting two old-growth forest polypore species. Entomologica Fennica, 12(1), 3-14.

Krivosheina, N. P. (2008). Macromycete fruit bodies as a habitat for dipterans (Insecta, Diptera). Entomological Review, 88(7), 778-792. https://doi.org/10.1134/S0013873808070038

Lamit, L. J., Busby, P. E., Lau, M. K., Compson, Z. G., Wojtowicz, T., Keith, A. R., ... Whitham, T. G. (2015). Tree genotype mediates covariance among communities from microbes to lichens and arthropods. Journal of Ecology, 103(4), 840-850. https://doi.org/10.1111/1365-2745. 12416

Lawrence, J. F. (1989). Mycophagy in Coleoptera: Feeding strategies and morphological adaptations. In N. Wilding, N. M. Collins, P. M. 
Hammond, \& J. F. Webber (Eds.), Insect-fungus interactions (pp. 2-23). London, UK: Academic Press Inc.

Lipkow, E., \& Betz, O. (2005). Staphylinidae and fungi. Faunistisch-Oekologische Mitteilungen, 8(9-10), 383-411. Retrieved from biosis: PREV200600082712

Martin, M. (2011). Cutadapt removes adapter sequences from highthroughput sequencing reads. EMBnet. Journal, 17(1), 10. https://doi. org/10.14806/ej.17.1.200

McMurdie, P. J., \& Holmes, S. (2013). Phyloseq: An R package for reproducible interactive analysis and graphics of microbiome census data. PLoS ONE, 8(4), https://doi.org/10.1371/journal.pone. 0061217

Morris, R. J., Gripenberg, S., Lewis, O. T., \& Roslin, T. (2014). Antagonistic interaction networks are structured independently of latitude and host guild. Ecology Letters, 17(3), 340-349. https://doi.org/10.1111/ ele.12235

Mouquet, N., Devictor, V., Meynard, C. N., Munoz, F., Bersier, L.-F., Chave, J., ... Thuiller, W. (2012). Ecophylogenetics: Advances and perspectives. Biological Reviews, 87(4), 769-785. https://doi.org/10. 1111/j.1469-185X.2012.00224.x

Niemelä, J. (1997). Invertebrates and boreal forest management. Conservation Biology, 11(3), 601-610. https://doi.org/10.1046/j.1523-1739. 1997.06008.x

O'Connell, T., \& Bolger, T. (1997). Stability, ephemerality and dispersal ability: Microarthropod assemblages on fungal sporophores. Biological Journal of the Linnean Society, 62(1), 111-131. https://doi.org/10. 1006/bijl.1997.0144

Økland, B. (1994). Mycetophilidae (Diptera), an insect group vulnerable to forestry practices? A comparison of clearcut, managed and seminatural spruce forests in southern Norway. Biodiversity and Conservation, 3(1), 68-85. https://doi.org/10.1007/BF00115334

Oksanen, A. J., Blanchet, F. G., Kindt, R., Legendre, P., Minchin, P. R., Hara, R. B. O., ... Wagner, H. (2015). vegan: Community ecology package. R package version 2.2-1. Retrieved from http://CRAN.R-project. org/package=vegan. doi:ISBN 0-387-95457-0

Orledge, G. M., \& Reynolds, S. E. (2005). Fungivore host-use groups from cluster analysis: Patterns of utilisation of fungal fruiting bodies by ciid beetles. Ecological Entomology, 30(6), 620-641. https://doi.org/10. 1111/j.0307-6946.2005.00727.x

Ovaskainen, O., Tikhonov, G., Norberg, A., Guillaume Blanchet, F., Duan, L., Dunson, D., ... Abrego, N. (2017). How to make more out of community data? A conceptual framework and its implementation as models and software. Ecology Letters, 20(5), 561-576. https://doi. org/10.1111/ele.12757

Pellissier, L., Albouy, C., Bascompte, J., Farwig, N., Graham, C., Loreau, M., ... Gravel, D. (2018). Comparing species interaction networks along environmental gradients. Biological Reviews, 93(2), 785-800. https://doi.org/10.1111/brv.12366

Pent, M., Hiltunen, M., Põldmaa, K., Furneaux, B., Hildebrand, F., Johannesson, H., ... Bahram, M. (2018). Host genetic variation strongly influences the microbiome structure and function in fungal fruitingbodies. Environmental Microbiology, 20, 1641-1650. https://doi.org/ 10.1111/1462-2920.14069

Pent, M., Põldmaa, K., \& Bahram, M. (2017). Bacterial communities in boreal forest mushrooms are shaped both by soil parameters and host identity. Frontiers in Microbiology, 8(MAY), 1-13. https://doi.org/ 10.3389/fmicb.2017.00836

Pilipenko, V. E., Salmela, J., \& Vesterinen, E. J. (2012). Description and DNA barcoding of Tipula (Pterelachisus) recondita sp. $\mathrm{n}$. from the Palaearctic region (Diptera, Tipulidae). ZooKeys, 192, 51-65. https://d oi.org/10.3897/zookeys.192.2364

Piñol, J., Senar, M. A., \& Symondson, W. O. C. (2018). The choice of universal primers and the characteristics of the species mixture determines when DNA metabarcoding can be quantitative. Molecular Ecology. https://doi.org/10.1111/mec.14776
Põldmaa, K., Jürgenstein, S., Bahram, M., Teder, T., \& Kurina, O. (2015). Host diversity and trophic status as determinants of species richness and community composition of fungus gnats. Basic and Applied Ecology, 16(1), 46-53. https://doi.org/10.1016/j.baae. 2014.10.004

Põldmaa, K., Kaasik, A., Tammaru, T., Kurina, O., Jürgenstein, S., \& Teder, T. (2016). Polyphagy on unpredictable resources does not exclude host specialization: Insects feeding on mushrooms. Ecology, 97(10), 2824-2833. https://doi.org/10.1002/ecy.1526

Polevoi, A., Jakovlev, J., \& Zaitzev, A. (2006). Fungus gnats (Diptera Bolitophilidae, Diadocidiidae, Keroplatidae and Mycetophilidae) new to Finland. Entomologica Fennica, 17(June), 161-169.

R Core Team (2017). R: A language and environment for statistical computing. $\mathrm{R}$ Foundation for Statistical Computing, Vienna, Austria. Retrieved from https://www.r-project.org/

Ratnasingham, S., \& Hebert, P. D. N. (2013). A DNA-based registry for all animal species: The barcode index number (BIN) system. PLoS ONE, 8 (7), e66213. https://doi.org/10.1371/journal.pone.0066213

Rohland, N., \& Reich, D. (2012). Cost-effective, high-throughput DNA sequencing libraries for multiplexed target capture. Genome Research, 22(5), 939-946. https://doi.org/10.1101/gr.128124.111

Roslin, T., \& Majaneva, S. (2016). The use of DNA barcodes in food web construction-Terrestrial and aquatic ecologists unite!. Genome, 59(9), 603-628. https://doi.org/10.1139/gen-2015-0229

Salo, P., Niemelä, T., \& Salo, U. (2009). Suomen sieniopas. WSOY.

Schigel, D. S. (2012). Fungivory and host associations of Coleoptera: A bibliography and review of research approaches. Mycology an International Journal on Fungal Biology, 3(4), 258-272. https://doi.org/10. 1080/21501203.2012.741078

Schoch, C. L., Seifert, K. A., Huhndorf, S., Robert, V., Spouge, J. L., Levesque, C. A., ... Schindel, D. (2012). Nuclear ribosomal internal transcribed spacer (ITS) region as a universal DNA barcode marker for fungi. Proceedings of the National Academy of Sciences of the United States of America, 109(16), 1-6. https://doi.org/10.1073/pnas.1117018109

Seifert, K. A. (2009). Progress towards DNA barcoding of fungi. Molecular Ecology Resources, 9(Suppl. 1), 83-89. https://doi.org/10.1111/j. 1755-0998.2009.02635.x

Selonen, V. A. O., Ahlroth, P., \& Kotiaho, J. S. (2005). Anthropogenic disturbance and diversity of species: Polypores and polypore-associated beetles in forest, forest edge and clear-cut. Scandinavian Journal of Forest Research, 20(Suppl. 6), 49-58. https://doi.org/10.1080/ 14004080510041002

Ševčík, J. (2006). Diptera associated with fungi in the Czech and Slovak Republics. Slezské Zemské Muzseum Opava, 55, 1-84.

Shokralla, S., Porter, T. M., Gibson, J. F., Dobosz, R., Janzen, D. H., Hallwachs, W., ... Hajibabaei, M. (2015). Massively parallel multiplex DNA sequencing for specimen identification using an Illumina MiSeq platform. Scientific Reports, 5, 9687. https://doi.org/10.1038/sre p09687

Šigut, M., Kostovčík, M., Šigutová, H., Hulcr, J., Drozd, P., \& Hrček, J. (2017). Performance of DNA metabarcoding, standard barcoding, and morphological approach in the identification of host-parasitoid interactions. PLoS ONE, 12(12), e0187803. https://doi.org/10.1371/journa I.pone.0187803

Søli, G. E. E., Vockeroth, J. R., \& Matile, L. (2000). A.4. Families of Sciaroidea. Manual of Palaearctic Diptera. Appendix, 49-92.

Ståhls, G., Ribeiro, E., \& Hanski, I. (1989). Fungivorous Pegomya flies: Spatial and temporal variation in a guild of competitors. Annales Zoologici Fennici, 26, 103-112.

Taberlet, P., Coissac, E., Pompanon, F., Brochmann, C., \& Willerslev, E. (2012). Towards next-generation biodiversity assessment using DNA metabarcoding. Molecular Ecology, 21(8), 2045-2050. https://doi.org/ 10.1111/j.1365-294X.2012.05470.x

Tedersoo, L., Bahram, M., Polme, S., Koljalg, U., Yorou, N. S., Wijesundera, R., ... Abarenkov, K. (2014). Global diversity and geography of 
soil fungi. Science, 346(6213), 1256688. https://doi.org/10.1126/scie nce. 1256688

Thorn, S., Müller, J., Bässler, C., Gminder, A., Brandl, R., \& Heibl, C. (2015). Host abundance, durability, basidiome form and phylogenetic isolation determine fungivore species richness. Biological Journal of the Linnean Society, 114(3), 699-708. https://doi.org/10.1111/bij.12447

Toju, H., Tanabe, A. S., Yamamoto, S., \& Sato, H. (2012). High-coverage ITS primers for the DNA-based identification of ascomycetes and basidiomycetes in environmental samples. PLoS ONE, 7(7), e40863. https://doi.org/10.1371/journal.pone.0040863

UNITE Community (2017). UNITE QIIME release. Version 01.12.2017. UNITE community. https://doi.org/10.15156/bio/587481

Vesterinen, E. J., Ruokolainen, L., Wahlberg, N., Peña, C., Roslin, T., Laine, V. N., ... Lilley, T. M. (2016). What you need is what you eat? Prey selection by the bat Myotis daubentonii. Molecular Ecology, 25(7), 1581-1594. https://doi.org/10.1111/mec.13564

Wirta, H. K., Hebert, P. D. N., Kaartinen, R., Prosser, S. W., Várkonyi, G., \& Roslin, T. (2014). Complementary molecular information changes our perception of food web structure. Proceedings of the National Academy of Sciences, 111(5), 1885-1890. https://doi.org/10.1073/ pnas.1316990111

Wirta, H. K., Várkonyi, G., Rasmussen, C., Kaartinen, R., Schmidt, N. M., Hebert, P. D. N., ... Roslin, T. (2016). Establishing a community-wide DNA barcode library as a new tool for arctic research. Molecular Ecology Resources, 16(3), 809-822. https://doi.org/10.1111/1755-0998.12489

Wirta, H. K., Vesterinen, E. J., Hambäck, P. A., Weingartner, E., Rasmussen, C., Reneerkens, J., ... Roslin, T. (2015). Exposing the structure of an Arctic food web. Ecology and Evolution, 5(17), 3842-3856. https://doi.org/10.1002/ece3.1647

Yamashita, S., Ando, K., Hoshinga, H., Ito, N., Katayama, Y., Kawanabe, M., ... Itioka, T. (2015). Food web structure of the fungivorous insect community on bracket fungi in a Bornean tropical rain forest. Ecological Entomology, 40(4), 390-400. https://doi.org/10.1111/een.12200
Yamashita, S., \& Hijii, N. (2003). Effects of mushroom size on the structure of a mycophagous arthropod community: Comparison between infracommunities with different types of resource utilization. Ecological Research, 18(2), 131-143. https://doi.org/10.1046/j.1440-1703. 2003.00541.x

Yu, D. W., Ji, Y., Emerson, B. C., Wang, X., Ye, C., Yang, C., \& Ding, Z. (2012). Biodiversity soup: Metabarcoding of arthropods for rapid biodiversity assessment and biomonitoring. Methods in Ecology and Evolution, 3(4), 613-623. https://doi.org/10.1111/j.2041-210X.2012. 00198.x

Zeale, M. R. K., Butlin, R. K., Barker, G. L. A., Lees, D. C., \& Jones, G. (2011). Taxon-specific PCR for DNA barcoding arthropod prey in bat faeces. Molecular Ecology Resources, 11(2), 236-244. https://doi.org/ 10.1111/j.1755-0998.2010.02920.x

\section{SUPPORTING INFORMATION}

Additional supporting information may be found online in the Supporting Information section at the end of the article.

How to cite this article: Koskinen J, Roslin T, Nyman T, Abrego N, Michell C, Vesterinen EJ. Finding flies in the mushroom soup: Host specificity of fungus-associated communities revisited with a novel molecular method. Mol Ecol. 2018;00:1-13. https://doi.org/10.1111/mec.14810 